\title{
Recombinant human bone morphogenetic protein (rhBMP)9 induces osteoblast differentiation when combined with demineralized freeze-dried bone allografts (DFDBAs) or biphasic calcium phosphate (BCP)
}

\author{
Masako Fujioka-Kobayashi ${ }^{1,2,3}$ • Benoit Schaller ${ }^{2}$ - Yufeng Zhang ${ }^{4}$. \\ Umadevi Kandalam $^{5}$ - Maria Hernandez ${ }^{1} \cdot$ Richard J. Miron $^{1}$
}

Received: 8 July 2016 / Accepted: 13 October 2016

(C) Springer-Verlag Berlin Heidelberg 2016

\begin{abstract}
Objectives Recently, recombinant human bone morphogenetic protein 9 (rhBMP9) has been characterized as one of the most osteogenic growth factors among the 15 human BMPs. The aim of the present study was to investigate the effects of rhBMP9 in comparison to the clinically utilized rhBMP2 on in vitro cell behavior when combined with two bone graft materials including demineralized freeze-dried bone allografts (DFDBAs) and biphasic calcium phosphate (BCP).

Materials and methods The absorption and release kinetics of rhBMPs from DFDBA and BCP were investigated by ELISA. Moreover, murine bone stromal ST2 cell behavior was investigated on DFDBA or BCP seeded on (1) graft only, (2) rhBMP2 (10 ng/ml), (3) rhBMP2 (100 ng/ml), (4) rhBMP9 $(10 \mathrm{ng} / \mathrm{ml})$, and (5) rhBMP9 $(100 \mathrm{ng} / \mathrm{ml})$. The effects of rhBMPs on DFDBA and BCP were assessed for cell adhesion, proliferation, and osteoblast differentiation by alkaline phosphatase (ALP) activity, alizarin red staining, and realtime PCR for genes encoding Runx2, ALP, and bone sialoprotein (BSP).
\end{abstract}

Richard J. Miron

rmiron@nova.edu

1 Department of Periodontology, College of Dental Medicine, Nova Southeastern University, Fort Lauderdale, FL, USA

2 Department of Cranio-Maxillofacial Surgery, Bern University Hospital, Inselspital, Bern, Switzerland

3 Department of Oral Surgery, Institute of Biomedical Sciences, Tokushima University Graduate School, Tokushima, Japan

4 Department of Oral Implantology, University of Wuhan, Wuhan, China

5 Department of Pediatric Dentistry, College of Dental Medicine, Nova Southeastern University, Fort Lauderdale, FL, USA
Results While both BMPs were gradually released from DFDBA and BCP over time, significantly higher adsorption was observed on BCP when compared to DFDBA. Cell attachment and proliferation was higher on $\mathrm{BCP}$ with little influence of either rhBMP2/9. Despite rhBMPs having relatively no effect on cell attachment/proliferation, a pronounced and marked effect was observed on osteoblast differentiation for both rhBMP2/9. Interestingly, it was observed that rhBMP9 induced significantly higher ALP activity, alizarin red staining, and messenger RNA (mRNA) levels of ALP and BSP when compared to rhBMP2. Our results also revealed higher differentiation for rhBMP2/9 with BCP when compared to DFDBA most likely as a result of higher growth factor adsorption.

Conclusion While both rhBMP2/9 combined with DFDBA or BCP induced osteoblast differentiation, rhBMP9 induced greater osteoblast differentiation when compared to rhBMP2. Clinical relevance rhBMP9 may be a recombinant growth factor with higher potential to induce new bone formation when compared to rhBMP2. Further in vivo studies are necessary to characterize its regenerative potential in various animal models.

Keywords Bone morphogenetic proteins - BMP2 - BMP9 . Demineralized freeze-dried bone allografts - DFDBA . Biphasic calcium phosphate $\cdot \mathrm{BCP} \cdot$ Bone tissue engineering · Bone regeneration

\section{Introduction}

Bone morphogenetic proteins (BMPs) were discovered over 40 years ago displaying great potential to act as potent growth factors capable of facilitating bone induction [1-3]. 
Recombinant human (rh) BMP2 has been FDA-approved for the regeneration of various bone defects utilized in the fields of orthopedic and oral maxillofacial surgery due to their osteoinductive potential [4-6]. Despite its widespread use, it is interesting to note that several comparative studies have revealed in fact that BMP2 is not the most osteopromote growth factor among the BMP family. About a decade ago, it was reported in several adenovirus transfection experiments (gene therapy) that specifically $a d$ BMP9 had greater osteogenic potential as assessed both in vitro and in vivo by means of comparative studies of all known BMPs [7, 8].

BMP9 is predominantly expressed in the liver [9] yet acts as a major modulator of osteogenesis playing important roles in the cell commitment and differentiation of mesenchymal stem cells $[10,11]$. Until recently however, the osteogenic potential of BMP9 had only been investigated through a gene therapy approach by utilizing adenovirus transfection, an area of research still not approved by the FDA for clinical use. Recently, our group investigated for the first time the recombinant human growth factor BMP9 (rhBMP9) and demonstrated its greater osteogenic properties when compared to rhBMP2 when combined with either a xenograft bone graft or collagen membrane [12, 13]. For a further understanding of the regenerative potential of rhBMP9 for various bone tissue engineering applications, the aim of future research is to further characterize the ability of rhBMP9 to influence osteoblast behavior on other bone biomaterials.

Bone grafts are commonly classified into four groups including autografts, allografts, xenografts, and alloplasts [14]. While autogenous bone has been characterized as the gold standard for bone regeneration, disadvantages including additional donor site morbidity, limited available supply, additional surgical time, and costs have also been reported necessitating alternatives $[15,16]$. Demineralized freeze-dried bone allografts (DFDBAs) and synthetic biphasic calcium phosphate (BCP) have been extensively utilized in regenerative dentistry as they possess excellent osteoconductive potential $[14,17-20]$. Therefore, the aim of the present study was to assess if specifically rhBMP9 could further induce their ostepromotive potential by loading an osteoinductive growth factor within their matrix. First, the three-dimensional morphology of each bone graft was investigated by scanning electron microscopy. Thereafter, the ability for either rhBMP2 and rhBMP9 to adsorb to bone-grafting materials and be released over time was investigated. Lastly, the effects of rhBMP9 in combination with either DFDBA or BCP were investigated on cell attachment, proliferation, and differentiation toward bone-forming osteoblasts in comparison to rhBMP2.

\section{Materials and methods}

\section{Regents and cell line}

rhBMP2 and rhBMP9 (CHO cell-derived) were purchased from R\&D Systems Inc. (Minneapolis, MN). DFDBA (DBX Demineralized Bone Matrix Mix; Synthes Inc., West Chester, $\mathrm{PA}$ ) and $\mathrm{BCP}$ (maxresorb ${ }^{\circledR}$ granules, $0.5-1.0 \mathrm{~mm}, \mathrm{~S}$ size; Botiss AG, Berlin, Germany), which is composed by $60 \%$ hydroxyapatite (HA) and $40 \% \beta$-tricalcium phosphate $(\beta$ TCP), were used in the present study. For all in vitro cell experiments, the following six groups for each bone graft material were assessed: (1) control tissue culture plastic, (2) control bone graft only, (3) bone graft + rhBMP2 low (10 ng/ $\mathrm{ml})$, (4) bone graft + rhBMP2 high $(100 \mathrm{ng} / \mathrm{ml})$, (5) bone graft + rhBMP9 low $(10 \mathrm{ng} / \mathrm{ml})$, and (6) bone graft + rhBMP9 high $(100 \mathrm{ng} / \mathrm{ml})$. Undifferentiated mouse bone stromal cell line ST2 was obtained from RIKEN Cell Bank (Tsukuba, Japan). Cells were cultured in a humidified atmosphere at $37{ }^{\circ} \mathrm{C}$ in growth medium consisting of DMEM (Gibco, Life Technologies, Carlsbad, CA), $10 \%$ fetal bovine serum (FBS, Gibco), and antibiotics (Gibco). For in vitro cell experiments, $10 \mathrm{mg}$ of bone graft was placed at the bottom of 24well dishes and pre-coated with rhBMP2 or rhBMP9 in DMEM for $5 \mathrm{~min}$, followed by cell seeding without rinsing unadsorbed proteins. Cells were seeded at a density of 10,000 cells in 24-well culture plates for cell adhesion and proliferation experiments and 50,000 cells per well in 24-well dishes for real-time PCR, alkaline phosphatase (ALP) assay, and alizarin red experiments. For experiments lasting longer than 5 days, medium was replaced twice weekly.

\section{Scanning electron microscopy}

Scanning electron microscopy (SEM) was utilized to study the morphological features of both bone-grafting materials. Either DFDBA or BCP granule samples were sputter coated by using an ion coater device with $10 \mathrm{~nm}$ of gold and analyzed microscopically by using a scanning electron microscope as previously described [21].

\section{BMP2 and BMP9 adsorption and release kinetics quantification with ELISA}

To determine the quantity of rhBMP2 and rhBMP9 adsorption to DFDBA or BCP, ELISA quantification assay was utilized. Briefly, after the coating period, incubation of $100 \mathrm{ng} / \mathrm{ml}$ of rhBMP2/9 onto DFDBA and BCP at $37^{\circ} \mathrm{C}$ in a shaking incubator, the remaining PBS solution, containing unattached protein, was collected and quantified by an ELISA Duoset kit for BMP2 (DY355, range $=46.90-3000 \mathrm{pg} / \mathrm{ml}$, R\&D Systems) and BMP9 (DY3209, range $=15.60-1000 \mathrm{pg} / \mathrm{ml}$, R\&D Systems). Of rhBMP2/9 in PBS without mixing with a 
biomaterial, $100 \mathrm{ng} / \mathrm{ml}$ was quantified by ELISA, and the amount of each protein was considered as positive control (total coated protein). Subtraction of total coated protein from the amount of un-adsorbed protein was used to determine the amount of adsorbed material to the surface of DFDBA and BCP as previously described [22]. Furthermore, in order to determine the quantity of rhBMP $2 / 9$ protein being released from DFDBA and BCP over time, coated grafts were soaked in $1 \mathrm{ml}$ of PBS and samples were collected at various time points including $15 \mathrm{~min}, 1 \mathrm{~h}, 8 \mathrm{~h}, 1,3$, and 10 days. All samples were quantified in duplicate, and three independent experiments were performed.

\section{Cell adhesion and proliferation assay}

ST2 cells were seeded in 24-well plates at a density of 10,000 cells per well either on (1) control tissue culture plastic, (2) bone graft only, (3) bone graft + rhBMP2 low (10 ng/ml), (4) bone graft + rhBMP2 high $(100 \mathrm{ng} / \mathrm{ml})$, (5) bone graft + rhBMP9 low (10 ng/ml), and (6) bone graft + rhBMP9 high $(100 \mathrm{ng} / \mathrm{ml})$. Cells were quantified using MTS assay (Promega, Madison, WI) by using an ELx808 Absorbance Reader (BIO-TEK, Winooski, VT) at 1, 3, and 5 days for cell proliferation as previously described [].

\section{Real-time PCR analysis}

Total RNA was isolated by using High Pure RNA Isolation Kit (Roche, Switzerland) at 3 and 14 days for osteoblast differentiation markers. Primer and probe sequences for genes encoding runt-related transcription factor 2 (Runx2), ALP, bone sialoprotein (BSP), and glyceraldehyde 3-phosphate dehydrogenase (GAPDH) were fabricated with primer sequences according to Table 1. Real-time RT-PCR was performed by using Roche Master Mix and quantified on an Applied Biosystems 7500 Real-Time PCR Machine. A Nanodrop 2000c (Thermo, Wilmington, DE) was used to quantify total RNA levels. The $\Delta \Delta \mathrm{Ct}$ method was used to

Table 1 PCR primers for genes encoding Runx2, ALP, BSP, and GAPDH

\begin{tabular}{ll}
\hline Gene & Primer sequence \\
\hline mRunx2 F & agggactatggcgtcaaaca \\
mRunx2 R & ggctcacgtcgctcatctt \\
mALP F & ggacaggacacacacacaca \\
mALP R & caaacaggagagccacttca \\
mBSP F & gcactccaactgcccaaga \\
mBSP R & tttggagccetgctttctg \\
mGAPDH F & aggtcggtgtgaacggatttg \\
mGAPDH R & Tgtagaccatgtagttgaggtca \\
a & \\
\hline
\end{tabular}

calculate gene expression levels normalized to GAPDH values and calibrated to control samples.

\section{ALP activity assay}

At 7 days, cells were quantified for alkaline phosphatase expression utilizing a cell imaging system as previously described [13]. Alkaline phosphatase activity was monitored by using leukocyte alkaline phosphatase kit (procedure no. 86 , Sigma). ST2 cells were fixed by immersion in a citrateacetone-formaldehyde fixative solution for $5 \mathrm{~min}$. Alkaline dye mixture were prepared by mixing $1 \mathrm{ml}$ sodium nitrite solution and $1 \mathrm{ml}$ of fast red violet alkaline solution dissolved in $45 \mathrm{ml}$ of distilled water and $1 \mathrm{ml}$ of Naphtol AS-Bl alkaline solution. Surfaces were then placed in alkaline dye mixture solution for $20 \mathrm{~min}$ protected from light followed by rinsing in deionized water. All images were captured on a Wild Heerbrugg M400 ZOOM Makroskop (WILD HEERBRUGG, Heerbrugg, Switzerland) at the same magnification and light intensity and imported into ImageJ software (NIH, Bethesda, MD). Thresholding was used to generate percent stained values for each field of view.

\section{Mineralization assay}

ST2 cells were seeded in 24-well plates at a density of 50,000 cells per well with either (1) control tissue culture plastic, (2) bone graft only, (3) bone graft + rhBMP2 low (10 ng/ml), (4) bone graft + rhBMP2 high $(100 \mathrm{ng} / \mathrm{ml}),(5)$ bone graft + rhBMP9 low $(10 \mathrm{ng} / \mathrm{ml})$, and (6) bone graft + rhBMP9 high $(100 \mathrm{ng} / \mathrm{ml})$ in osteogenic differentiation medium (ODM), which consisted of DMEM supplemented with $10 \%$ FBS, $1 \%$ antibiotics, $50 \mu \mathrm{g} / \mathrm{ml}$ ascorbic acid (Sigma, St. Louis, $\mathrm{MO}$ ), and $10 \mathrm{mM} \beta$-glycerophosphate (Sigma) to promote osteoblast differentiation as previously described [23]. At 14 days post ST2 cell seeding, cells were fixed in $96 \%$ ethanol for $15 \mathrm{~min}$ and stained with $0.2 \%$ alizarin red solution (Alizarin Red S, Sigma) in water ( $\mathrm{pH}$ 6.4) at room temperature for $1 \mathrm{~h}$ as previously described [13, 23]. All images were captured, and the percentage of staining was evaluated in the same manner as the ALP assay.

\section{Statistical analysis}

All experiments were performed in triplicate with three independent experiments for each condition. Data were analyzed for statistical significance by using one-way analysis of variance with Tukey test $(* p$ values $<0.05$ was considered significant) by GraphPad Prism 6.0 software (GraphPad Software, Inc., La Jolla, CA). 


\section{Results}

SEM surface characteristics and BMP2 and BMP9 adsorption and release kinetics quantification with ELISA

In a first experiment, the three-dimensional surface morphology of DFDBA and BCP granules was investigated via SEM (Fig. 1). DFDBA demonstrated quite smooth surfaces that were devoid of any visible proteins on their surface (Fig. 1a, c). The high-resolution SEM imaging demonstrated slightly roughened surfaces (Fig. 1e). In contrast, numerous macropores and micropores were found on the surface of BCP grafting particles (Fig. 1b, d). The high-magnified SEM images of BCP demonstrated an extremely rough surface in surface nanotopographies (Fig. 1f). Thereafter, the potential of DFDBA and BCP granules to absorb and release BMP2 and BMP9 was analyzed via ELISA (Fig. 2). The total amount of adsorbed protein of either BMP2 or BMP9 to both bone-grafting materials revealed a near $80 \%$ adsorption (Fig. 2a, b). DFDBA loaded with rhBMP9 demonstrated
Fig. 1 SEM images of $\mathbf{a}, \mathbf{c}, \mathbf{e}$ DFDBA and $\mathbf{b}, \mathbf{d}, \mathbf{f}$ BCP particles at $\times 100, \times 400$, and $\times 1600$ magnifications

\section{DFDBA}
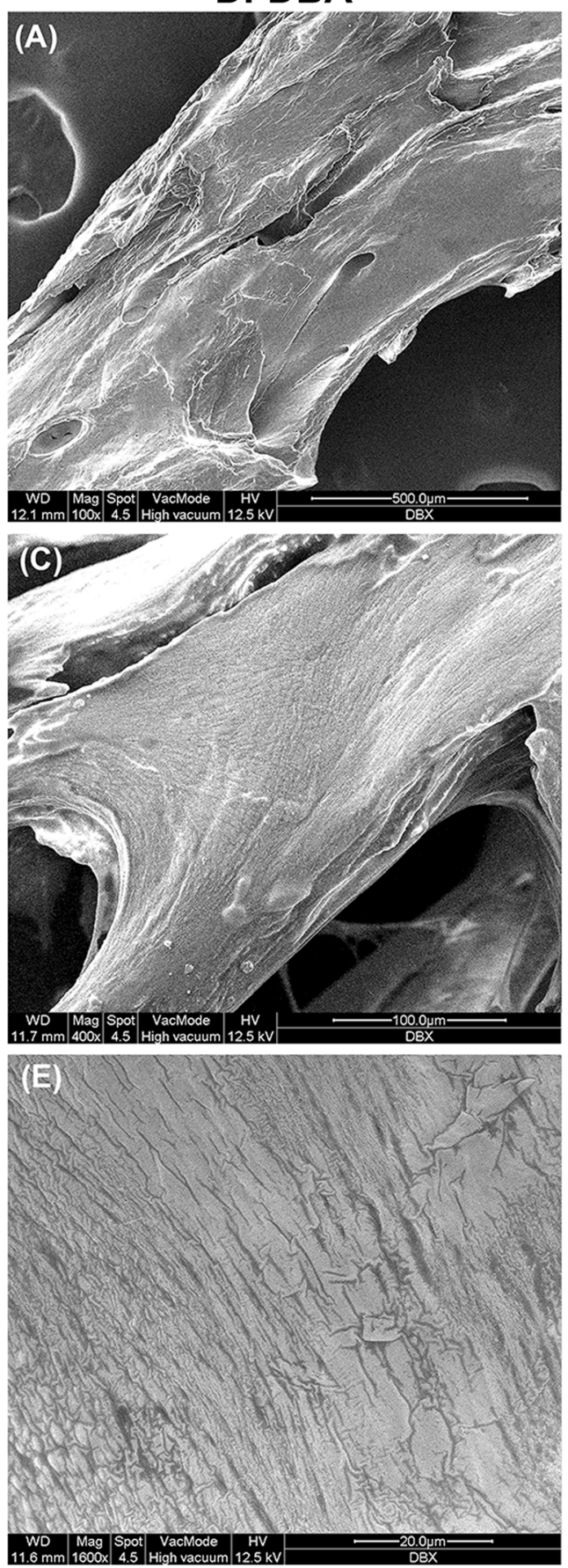

\section{BCP}
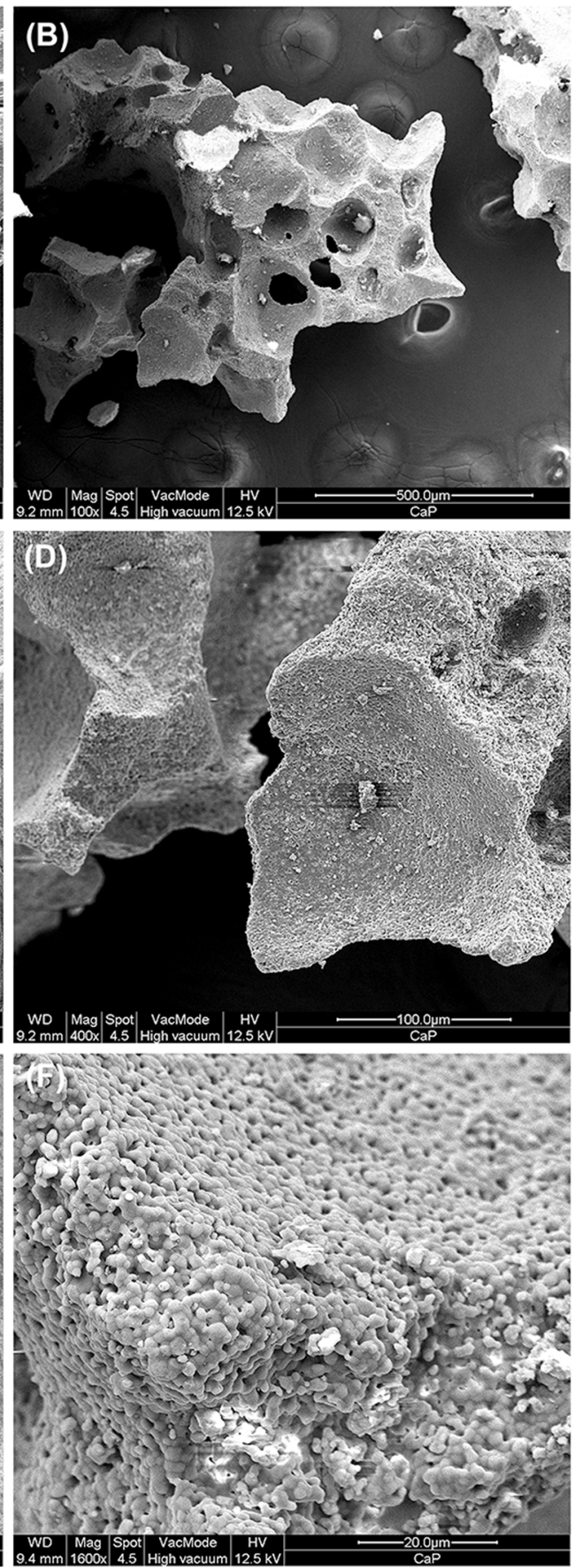

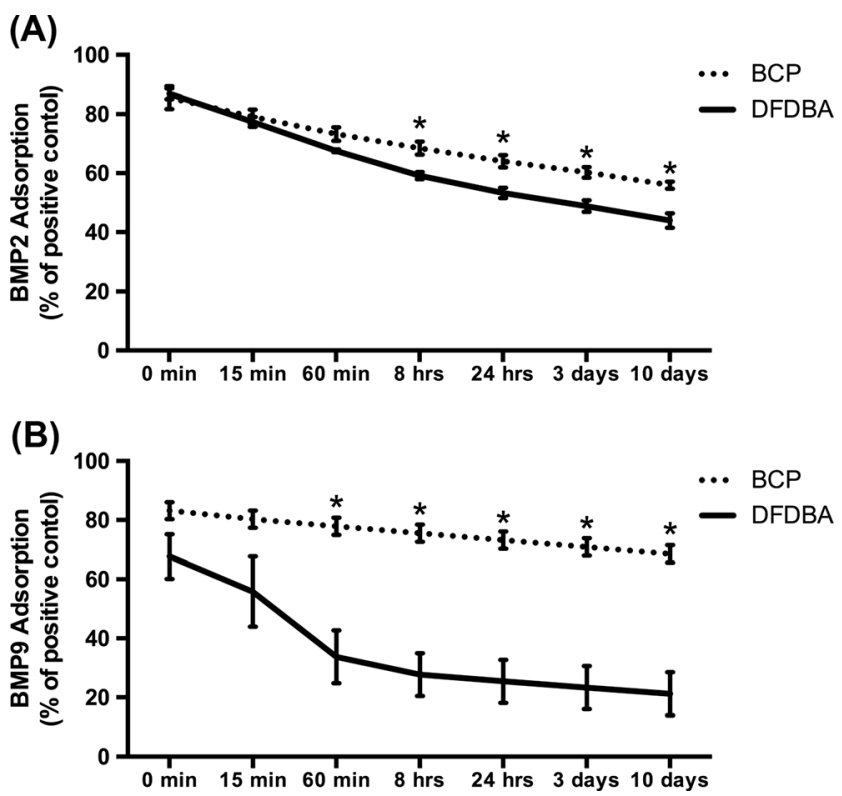

Fig. 2 BMP2 and BMP9 release kinetics from a DFDBA and $\mathbf{b}$ BCP granules at $15 \mathrm{~min}, 1 \mathrm{~h}, 8 \mathrm{~h}, 24 \mathrm{~h}, 3$ days, and 10 days after loading on each bone graft granules

lower adsorption potential around $70 \%$ the starting working concentration (Fig. 2b). Thereafter, it was found that the amount of BMP2/9 was slowly and gradually released over time from $15 \mathrm{~min}$ up to 10 days (Fig. 2a, b). First, it was observed that rhBMP2 loaded onto BCP demonstrated significantly higher remaining growth factor on the surface at $8 \mathrm{~h}, 1$, 3, and 10 days (Fig. 2a). A similar trend was also observed with rhBMP9 where BCP demonstrated significantly and markedly more BMP9 at $60 \mathrm{~min}, 8 \mathrm{~h}, 1,3$, and 10 days (Fig. 2b). These results demonstrate that BCP significantly increased BMP adsorption when compared to DFDBA from $8 \mathrm{~h}$ to 10 days for BMP2 and from 60 min up to 10 days for BMP9 (Fig. 2).

\section{Effects of rhBMP2 and rhBMP9 combined with DFDBA and BCP on ST2 cell adhesion and proliferation}

The effects of rhBMP2 and rhBMP9 combined with DFDBA and BCP were investigated on ST2 cell adhesion at $8 \mathrm{~h}$ and cell proliferation at 1, 3, and 5 days post seeding (Fig. 3). DFDBA significantly decreased ST2 cell attachment when compared to control tissue culture plastic at $8 \mathrm{~h}$ post cell seeding (Fig. 3a). Significantly lower values were further observed on DFDBA particles loaded with rhBMP2 high when compared to control DFDBA (Fig. 3a), whereas no significant differences between the other groups were observed (Fig. 3a). On the other hand, BCP did not influence cell adhesion when compared to control tissue culture plastic (Fig. 3b). A significant decrease in BCP particles loaded with rhBMP2 was observed when compared to BCP particles loaded with rhBMP9 low (Fig. 3b).
DFDBA and BCP were then tested for their abilities to induce cell proliferation (Fig. 3c, d). While DFDBA significantly suppressed cell growth by roughly $50 \%$ when compared with control plastic at 1,3 , and 5 days post seeding, no significant differences were observed among all groups seeded on DFDBA (Fig. 3c). Cell growth on BCP significantly decreased slightly when compared with control tissue culture plastic at 1 and 5 days post cell seeding, while no significant difference among all samples seeded on BCP at 1 and 5 days (Fig. 3d). These results seem to point to the fact that cells adhere and proliferate more favorably on BCP when compared to DFDBA (Fig. 3).

\section{Effects of rhBMP2 and rhBMP9 combined with DFDBA and $\mathrm{BCP}$ on osteoblastic differentiation}

We then investigated the osteogenic behavior of rhBMP2 and 9 when coated onto DFDBA and BCP particles utilizing ALP activity staining (Fig. 4), real-time PCR (Fig. 5), and alizarin red staining (Fig. 6). It was first observed that DFDBA itself did not promote ALP activity when compared to control tissue culture plastic (Fig. 4). Interestingly, however, DFDBA + rhBMP9 high samples significantly increased a 7-fold increase in ALP activity when compared with DFDBA only (Fig. 4a, c). Moreover, all DFDBA samples significantly decreased Runx2 messenger RNA (mRNA) levels when compared to control tissue plastic at 3 days post seeding (Fig. 5a), while DFDBA + rhBMP2 high and DFDBA + rhBMP9 high samples upregulated ALP mRNA levels up to 2-fold and BSP mRNA levels up to 6-fold, respectively, at 14 days when compared to control tissue culture plastic (Fig. 5c, e). Consistent with previous findings, alizarin red staining demonstrated that DFDBA + rhBMP2 high and DFDBA + rhBMP9 high samples significantly increased alizarin red staining at 14 days post cell seeding when compared with control tissue culture plastic (Fig. 6c).

In comparison, $\mathrm{BCP}+$ rhBMP9 demonstrated much greater osteogenic behavior when compared to either $\mathrm{BCP}+\mathrm{BCP} 9$ or DFDBA (Figs. 4, 5, and 6). While it was found that BCP + rhBMP2 high samples significantly increased a 10-fold increase in ALP activity when compared to control tissue culture plastic, both BCP + rhBMP9 low and BCP + rhBMP9 high samples significantly promoted a 50 -fold increase in ALP activity at 7 days post seeding when compared to control samples (Fig. 4b, d). Moreover, real-time PCR analysis demonstrated that only BCP + rhBMP9 high samples significantly upregulated ALP mRNA levels up to 2.5-fold when compared to control tissue culture plastic, $\mathrm{BCP}$ alone, and $\mathrm{BCP}+$ rhBMP2 low samples (Fig. 5d). In addition, BSP mRNA expression in the BCP + rhBMP9 high group was significantly higher when compared to all the other modalities (Fig. 5f). Once again, it was revealed that alizarin red staining demonstrated that while rhBMP2 samples significantly increased 


\section{(A)}

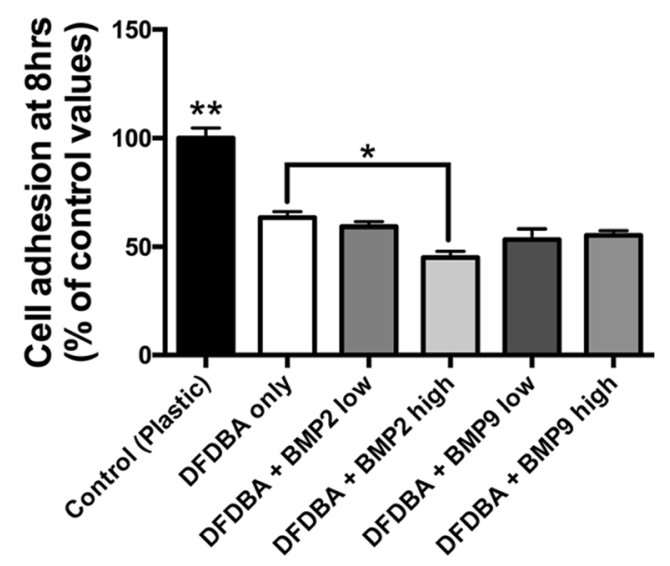

(C)

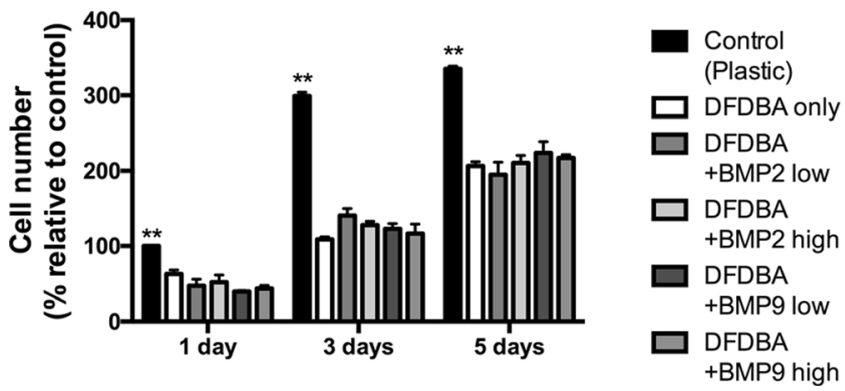

Fig. 3 Cell adhesion assay and proliferation assay of ST2 cells seeded on bone-grafting particles combined with rhBMP2 and rhBMP9. a, b ST2 cell attachment and $\mathbf{c}, \mathbf{d}$ proliferation on $\mathbf{a}, \mathbf{c}$ DFDBA or $\mathbf{b}, \mathbf{d}$ BCP with (1) control tissue culture plastic, (2) bone graft only, (3) rhBMP2 low (10 ng/ $\mathrm{ml})$, (4) rhBMP2 high (100 ng/ml), (5) rhBMP9 low (10 ng/ml), and (6)

alizarin red staining when compared with control samples, BCP particles combined with rhBMP9 (low or high) demonstrated marked and significantly higher increases in staining intensity when compared to BCP particles combined with rhBMP2 (Fig. 6b, d).

\section{Discussion}

In the present study, the osteopromotive potential of rhBMP9 combined with DFDBA and BCP was investigated in comparison to rhBMP2 in order to determine the ability for both growth factors to influence in vitro osteoblast behavior. DFDBA and BCP bone grafts were first investigated for their potential suitability as carriers for rhBMP2 and rhBMP9 (Fig. 2). It was first found that the adsorption potential of rhBMP2 and rhBMP9 was superior with BCP when compared to DFDBA (Fig. 2). One of the plausible explanations for this variation may be due to the fact that the rougher surface topography and numerous micropore structures present on the surface of BCP could favor protein absorption, whereas DFDBA possesses a relatively smooth surface [24].
(B)

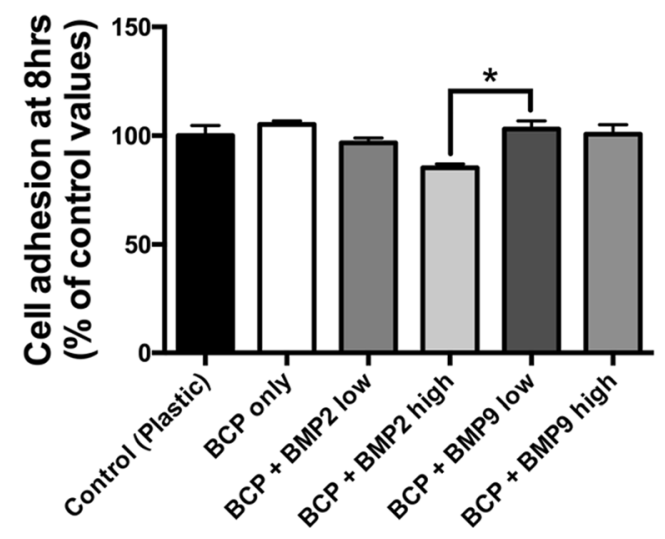

(D)

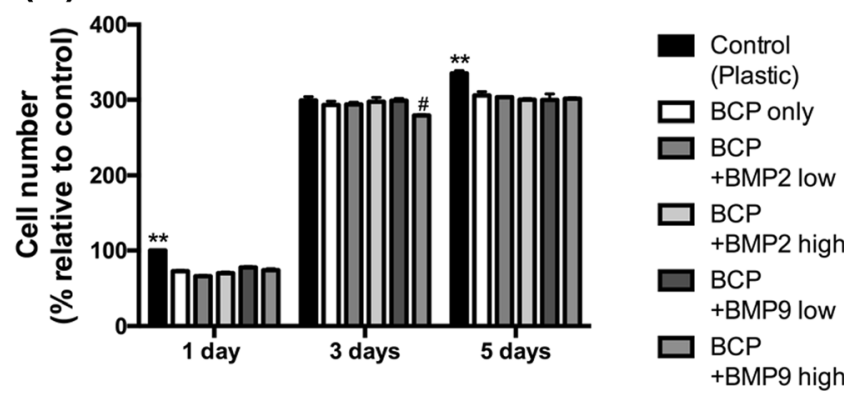

rhBMP9 high $(100 \mathrm{ng} / \mathrm{ml})$ at $8 \mathrm{~h}$ post cell seeding (cell attachment) and at 1,3 , and 5 days post cell seeding (cell proliferation). $\left({ }^{*} p<0.05\right.$, significant difference; $* * p<0.05$, significantly higher than all other modalities; ${ }^{\#} p<0.05$, significantly lower than all other modalities)

Moreover, it was found that rhBMPs released from both DFDBA and BCP continued gradually up to 10 days; however, BCP demonstrated significantly more BMP retention when compared to DFDBA, which suggested that BCP contributed to a more slow and gradual release of BMPs over time.

Thereafter, the cell behavior of progenitor cells was investigated in response to DFDBA and BCP loaded with either rhBMP2 or rhBMP9. It was observed that DFDBA significantly decreased ST2 cell attachment; however, BCP did not negatively influence the attachment of cells to bone-grafting particles when compared to control tissue culture plastic (Fig. 3a, b). A similar trend was also observed for cell proliferation where a significantly higher number of cells were found at all time points on BCP particles when compared to DFDBA (Fig. 3c, d). Interestingly, the addition of rhBMPs to either DFDBA or BCP had relatively no effect on cell adhesion or proliferation (Fig. 3). These findings are supported by similar other studies reporting that DFDBA significantly decreased cell proliferation on murine myoblast $\mathrm{C} 2 \mathrm{C} 12$ cells and on sarcoma osteogenic SaOS-2 cells [25, 26]. Moreover, in another study with BCP, it was reported that BCP had no effect on cell proliferation when compared to control tissue 
(A)
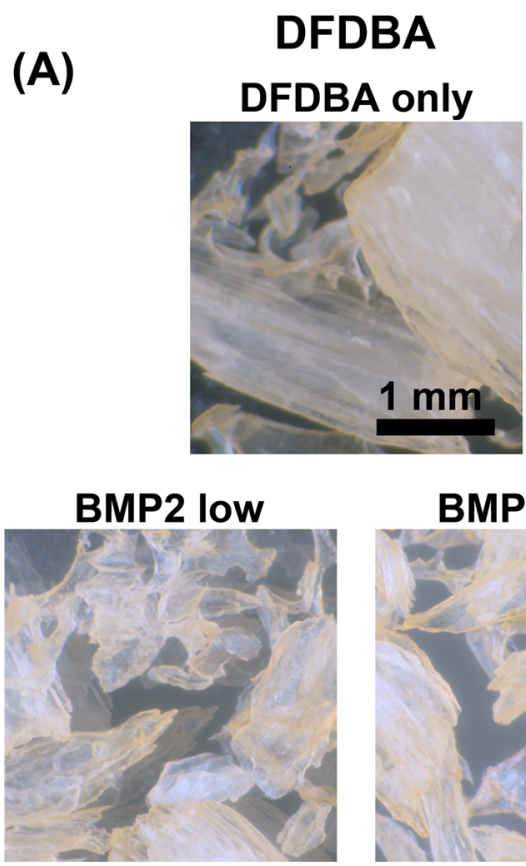

BMP9 low

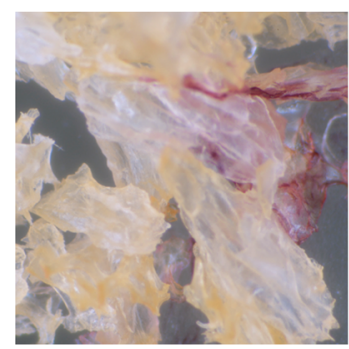

(C)

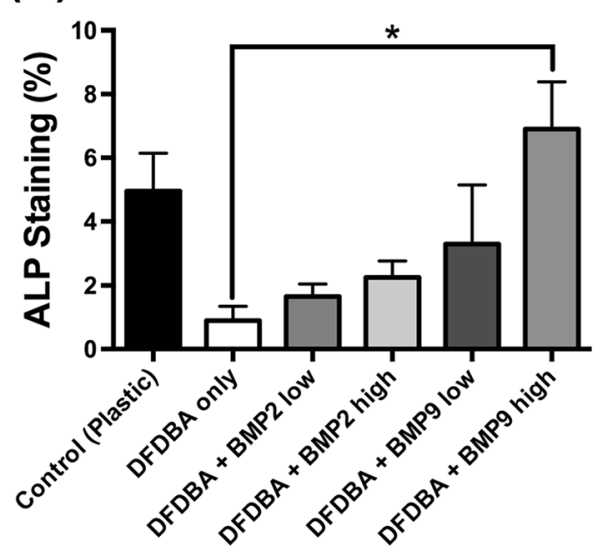

Fig. 4 a, b Images and $\mathbf{c}, \mathbf{d}$ quantified data of alkaline phosphatase (ALP) staining of ST2 cells on $\mathbf{a}, \mathbf{c}$ DFDBA or $\mathbf{b}, \mathbf{d}$ BCP with (1) control tissue culture plastic, (2) bone graft only, (3) rhBMP2 low (10 ng/ml), (4) rhBMP2 high (100 ng/ml), (5) rhBMP9 low (10 ng/ml), and (6) rhBMP9

culture plastic on rat primary osteoblasts at 3 days and on rabbit bone marrow mesenchymal stem cells at 1,3 , and 7 days $[27,28]$. In combination with the findings from our study, it may thus be concluded that the mesenchymal lineage cells found in these studies prefer the roughened surface found on
(B)
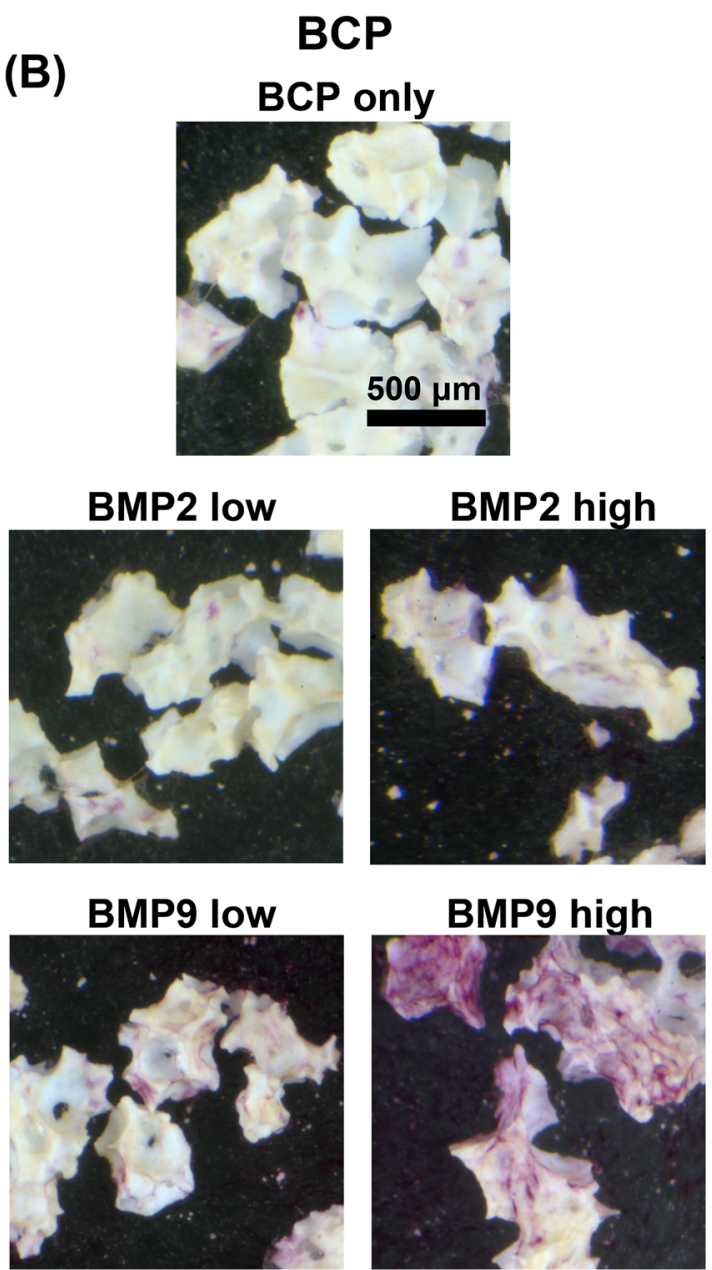

\section{BMP9 high}

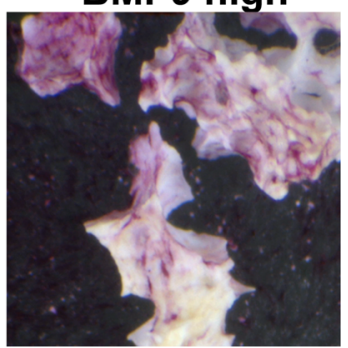

(D)

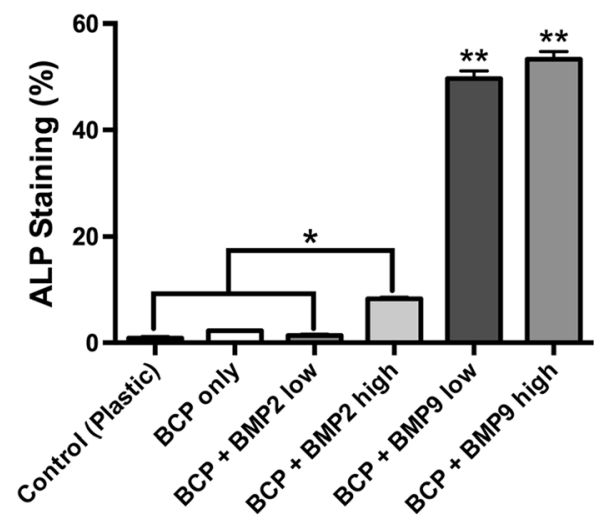

high $(100 \mathrm{ng} / \mathrm{ml})$ at 7 days post cell seeding. (*p $<0.05$, significant difference; $* * p<0.05$, significantly higher than all other treatment modalities)

BCP scaffolds when compared to the smoother DFDBA surface. Future research investigating the activated cell signaling pathways following cell attachment could reveal future cues as to why mesenchymal cells seem to favor $\mathrm{BCP}$ bone particles. 
Fig. 5 Real-time PCR of ST2 cells seeded on $\mathbf{a}, \mathbf{c}, \mathbf{e}$ DFDBA or $\mathbf{b}, \mathbf{d}, \mathbf{f}$ BCP with (1) control tissue culture plastic, (2) bone graft only, (3) rhBMP2 low (10 ng/ml), (4) rhBMP2 high (100 ng/ml), (5) rhBMP9 low (10 ng/ml), and (6) rhBMP9 high $(100 \mathrm{ng} / \mathrm{ml})$ for genes encoding a, b Runx $2, \mathbf{c}, \mathbf{d}$ ALP, and $\mathbf{e}, \mathbf{f}$ bone sialoprotein (BSP) at 3 and 14 days postseeding $(* * p<0.05$, significantly higher than all other treatment modalities; $* p<0.05$, significant difference)

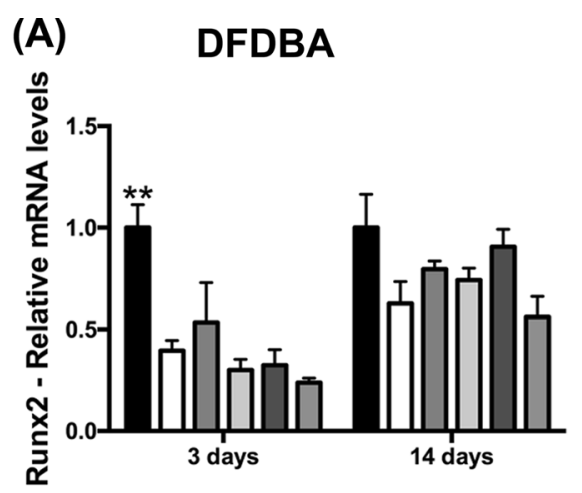

(C)

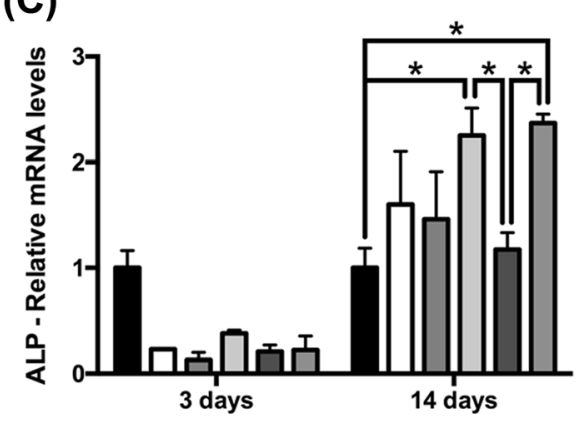

(E)

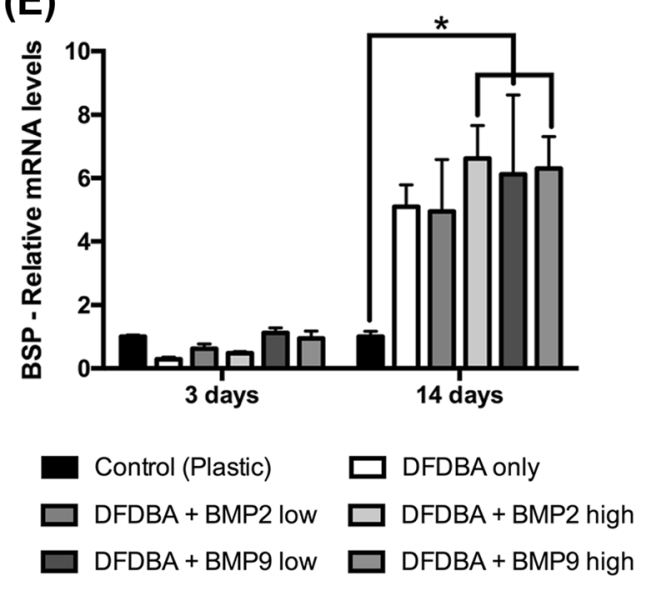

(B)

BCP

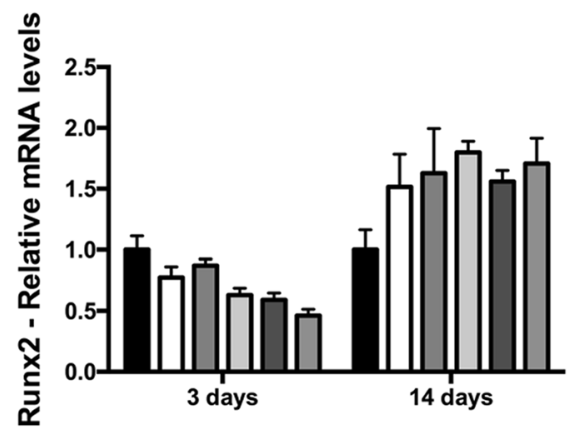

(D)

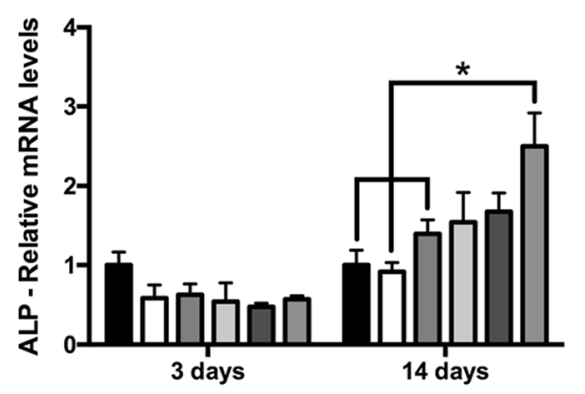

(F)

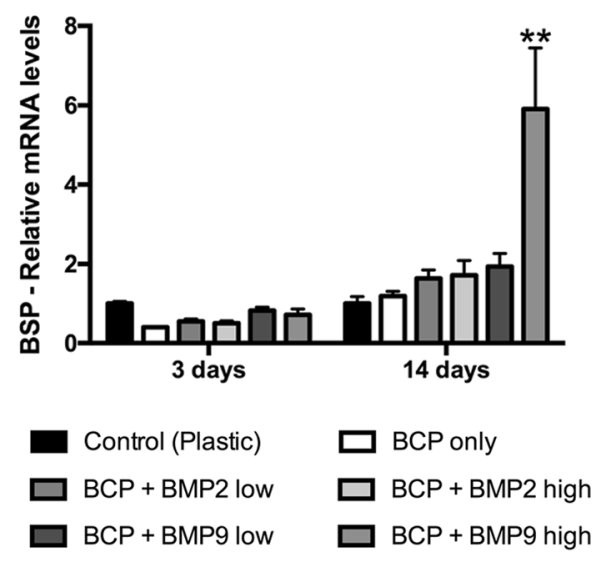

Furthermore, the osteogenic potential of rhBMP2 and rhBMP9 combined with either DFDBA or BCP was then investigated on osteoblast differentiation. While both bonegrafting material did not induce osteoblast differentiation when compared to control tissue culture plastic, both high concentrations of either rhBMP2 and rhBMP9 combined with DFDBA increased ALP mRNA levels up to 2-fold, BSP mRNA up to 6-fold, and enhanced alizarin red staining at 14 days post seeding when compared with control tissue culture plastic (Figs. 5c, e and 6c). A previous study reported that DFDBA combined with rhBMP2 induced effective bone formation capable of forming ectopic bone formation [29]. In the present study, the combination of DFDBA with rhBMP9 showed comparable osteopromotive potential to rhBMP2 with only alizarin red staining being significantly higher for rhBMP9 when compared to controls (Fig. 4c).

On the other hand, when rhBMP9 was combined with $\mathrm{BCP}$, a significant increase in osteogenic behavior even when compared to rhBMP2 was observed in all assays investigating osteoblast differentiation. Even low concentrations of rhBMP9 (10 ng/ml) combined with BCP significantly promoted further ALP activities and alizarin red staining when compared with rhBMP2 high. The different responses of rhBMP2 and rhBMP9 may be attributed to the fact that protein adsorption and activity is greatly influenced by protein conformation following adsorption. Furthermore, it remains unknown what may affect the timing of growth factor release of BMPs from the scaffold surface which might play a role on 
(A)

Control (without cells)

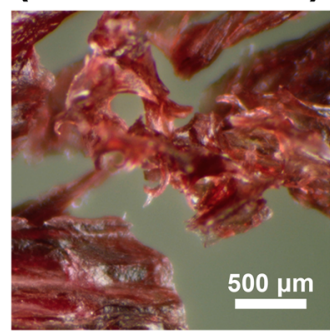

BMP2 low

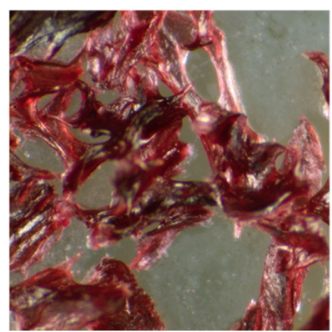

BMP9 low

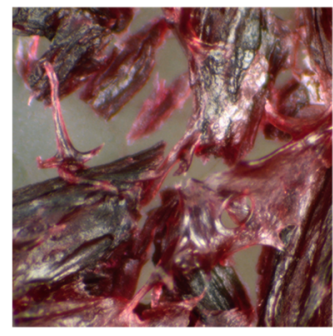

(C)
Control (with cells)

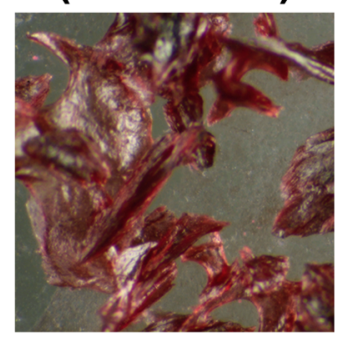

BMP2 high

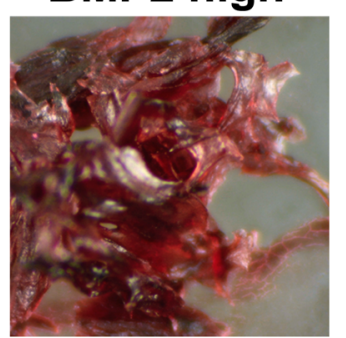

BMP9 high

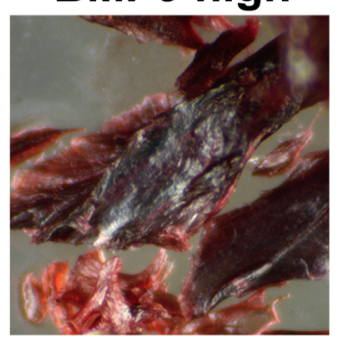

(B)
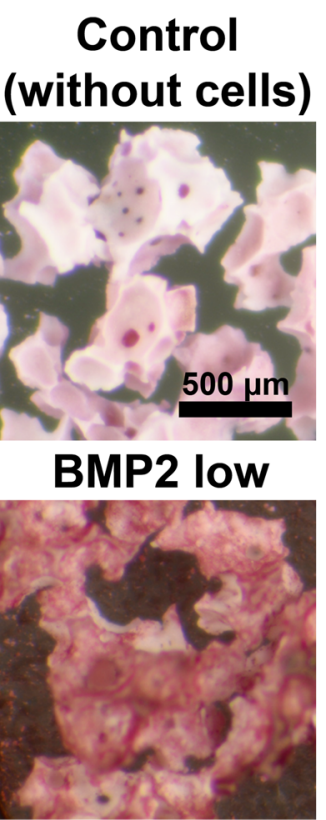

BMP9 low

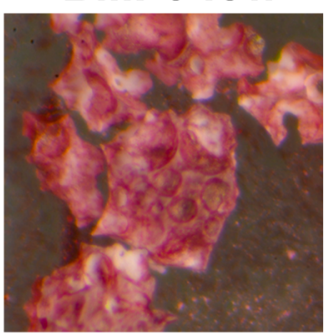

BCP

Control (with cells)

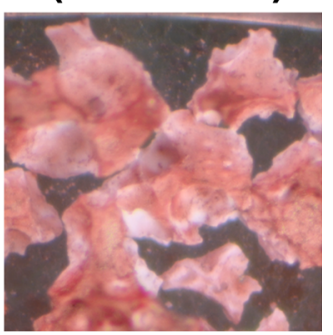

BMP2 high

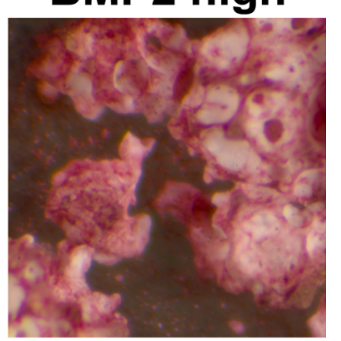

BMP9 high

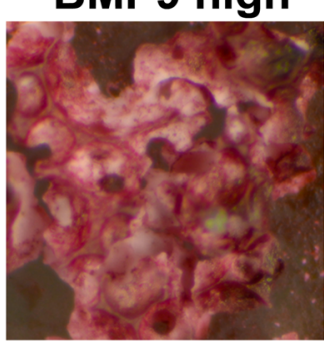

(D)

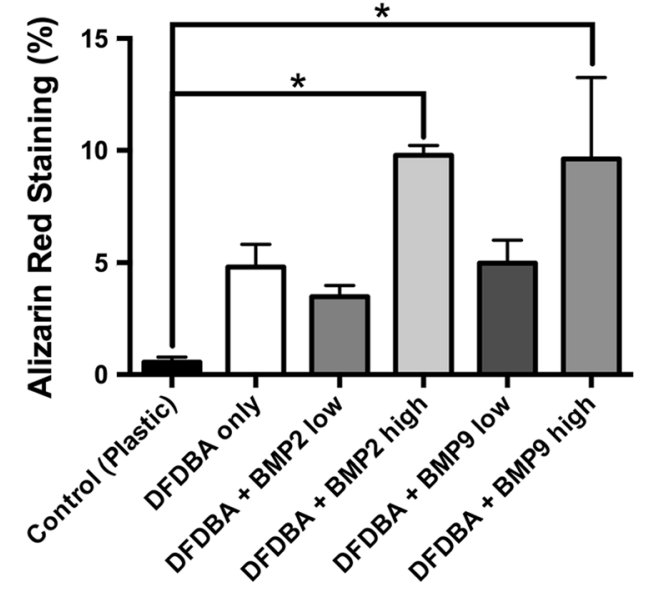

Fig. 6 Alizarin red staining of ST2 cells on a, c DFDBA or $\mathbf{b}, \mathbf{d}$ BCP with (1) control tissue culture plastic, (2) bone graft only, (3) rhBMP2 low (10 ng/ml), (4) rhBMP2 high (100 ng/ml), (5) rhBMP9 low (10 ng/ml),

osteoblast differentiation. Therefore, it remains to be investigated what may cause variability in protein adsorption of growth factors to bone-grafting materials and their relationship with osteoblast differentiation. Furthermore, it is unclear

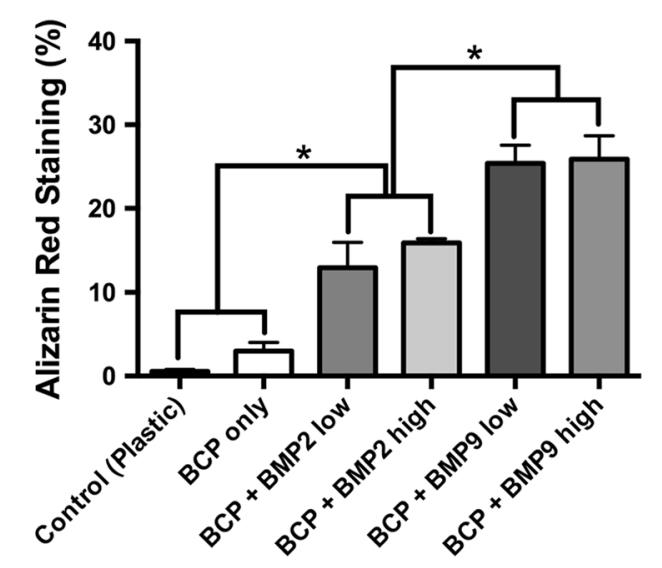

and (6) rhBMP9 high (100 ng/ml) at 14 days post seeding. a, b Images of alizarin red-stained calcium nodules and $\mathbf{c}, \mathbf{d}$ quantified evaluation of alizarin red staining. $\left({ }^{*} p<0.05\right.$, significant difference)

what factors induced the attractive osteogenic potential of rhBMP9. Based on adenovirus experiments, it might be attributed to the differences of canonical BMP signaling pathways. Both BMP2 and BMP9 have been shown to activate SMAD 
pathways through the phosphorylation of the transcription factors Smad $1 / 5 / 8$ by type I receptors in mesenchymal osteoblast cells [30, 31]. BMP stimulation induces BMP antagonist and noggin expression and inhibits BMP2 action; however, SMAD phosphorylation by BMP9 was not inhibited by exogenous noggin [30, 32, 33]. Furthermore, BMP3, a known inhibitor of BMP2-mediated osteogenesis, does not inhibit BMP9-mediated bone formation [8]. Further research utilizing rhBMP9 would benefit our understanding on the differential mechanisms that regulate osteogenesis in both BMP2 versus BMP9.

In the present study, it was clearly observed that rhBMP2/9 adsorbed better to BCP scaffolds and this, in turn, provided better cell behavior contributing to the differentiation of progenitor cells into mature osteoblasts. While the present data seems to favor the combination of growth factors with BCP (especially rhBMP9) on murine osteoprogenitor cells, it remains to be investigated what effect both these bone-grafting materials may have in human osteoprogenitor cells. Interestingly, Sreekumar et al. reported that rhBMP9 treatment showed significantly increased osteogenic activity including AP activity and Smad nuclear translocation when compared to the two clinically used rhBMP2 and rhBMP7 on primary human osteoblasts from 110 donors [34]. Therefore, future in vitro study on human cells and in vivo animal study are necessary to further characterize the regeneration potential of either bone graft when combined with rhBMP2 and rhBMP9.

\section{Conclusion}

The results from the present study demonstrate that both rhBMP2 and rhBMP9 combined to DFDBA and BCP displayed the potential to induce osteoblast differentiation. Interestingly, rhBMP9 in combination with BCP demonstrated the greatest stimulation of osteoblasts favoring significantly higher ALP activity, alizarin red staining, and expression of osteoblast differentiation markers ALP and BSP. While the results from the present study favors the use of rhBMP9 over rhBMP2, further in vivo studies remain necessary to further characterize the osteoinductive potential of rhBMP9 when combined with either DFDBA or BCP for future clinical use.

\section{Compliance with ethical standards}

Conflict of interest Masako Fujioka-Kobayashi declares that she has no conflict of interest. Benoit Schaller declares that he has no conflict of interest. Yufeng Zhang declares that he has no conflict of interest. Umadevi Kandalam declares that she has no conflict of interest. Maria Hernandez declares that she has no conflict of interest. Richard Miron declares that he has no conflict of interest.
Funding The work was by the Department of Cranio-Maxillofacial Surgery (Chair Professor Tateyuki Iizuka), Inselspital at the University of Bern, Switzerland.

Ethical approval This article does not contain any studies with human participants or animals performed by any of the authors.

Informed consent For this type of study, formal consent is not required.

\section{References}

1. Bragdon B, Moseychuk O, Saldanha S, King D, Julian J, Nohe A (2011) Bone morphogenetic proteins: a critical review. Cell Signal 23:609-620

2. Urist MR (1965) Bone: formation by autoinduction. Science 150 : 893-899

3. Urist MR, Strates BS (1971) Bone morphogenetic protein. J Dent Res 50:1392-1406

4. Huang YH, Polimeni G (2000) Qahash M and Wikesjo UM (2008) bone morphogenetic proteins and osseointegration: current knowledge-future possibilities. Periodontol 47:206-223. doi:10.1111/j.1600-0757.2007.00240.x

5. Jung RE, Glauser R, Scharer P, Hammerle CH, Sailer HF, Weber FE (2003) Effect of rhBMP-2 on guided bone regeneration in humans. Clin Oral Implants Res 14:556-568

6. McKay WF, Peckham SM, Badura JM (2007) A comprehensive clinical review of recombinant human bone morphogenetic protein2 (INFUSE® bone graft). Int Orthop 31:729-734

7. Cheng H, Jiang W, Phillips FM, Haydon RC, Peng Y, Zhou L, Luu HH, An N, Breyer B, Vanichakarn P, Szatkowski JP, Park JY, He TC (2003) Osteogenic activity of the fourteen types of human bone morphogenetic proteins (BMPs). J Bone Joint Surg Am 85-a:15441552

8. Kang Q, Sun MH, Cheng H, Peng Y, Montag AG, Deyrup AT, Jiang W, Luu HH, Luo J, Szatkowski JP, Vanichakarn P, Park JY, Li Y, Haydon RC, He TC (2004) Characterization of the distinct orthotopic bone-forming activity of 14 B.P. using recombinant adenovirus-mediated gene delivery. Gene Ther 11:1312-1320. doi:10.1038/sj.gt.3302298

9. Miller AF, Harvey SA, Thies RS, Olson MS (2000) Bone morphogenetic protein-9. An autocrine/paracrine cytokine in the liver $\mathrm{J}$ Biol Chem 275:17937-17945

10. Leblanc E, Trensz F, Haroun S, Drouin G, Bergeron E, Penton CM, Montanaro F, Roux S, Faucheux N, Grenier G (2011) BMP-9induced muscle heterotopic ossification requires changes to the skeletal muscle microenvironment. Journal of bone and mineral research : the official journal of the American Society for Bone and Mineral Research 26:1166-1177. doi:10.1002/jbmr.311

11. Lamplot JD, Qin J, Nan G, Wang J, Liu X, Yin L, Tomal J, Li R, Shui W, Zhang H, Kim SH, Zhang W, Zhang J, Kong Y, Denduluri S, Rogers MR, Pratt A, Haydon RC, Luu HH, Angeles J, Shi LL, He TC (2013) BMP9 signaling in stem cell differentiation and osteogenesis. American journal of stem cells 2:1-21

12. Fujioka-Kobayashi M, Sawada K, Kobayashi E, Schaller B, Zhang Y and Miron RJ (2016) Recombinant human bone morphogenetic protein 9 (rhBMP9) induced osteoblastic behaviour on a collagen membrane compared with rhBMP2. J Periodontol 87(6):e101-7. doi:10.1902/jop.2016.150561

13. Fujioka-Kobayashi M, Sawada K, Kobayashi E, Schaller B, Zhang Y and Miron RJ (2016) Osteogenic potential of rhBMP9 combined 
with a bovine-derived natural bone mineral scaffold compared to rhBMP2. Clin Oral Implants Res. doi:10.1111/clr.12804

14. Nazirkar G, Singh S, Dole V, Nikam A (2014) Effortless effort in bone regeneration: a review. Journal of international oral health: JIOH 6:120

15. Miron RJ, Sculean A, Shuang Y, Bosshardt DD, Gruber R, Buser D, Chandad F, Zhang Y (2015) Osteoinductive potential of a novel biphasic calcium phosphate bone graft in comparison with autographs, xenografts, and DFDBA. Clin Oral Implants Res. doi:10.1111/clr.12647

16. Miron RJ, Zhang Q, Sculean A, Buser D, Pippenger BE, Dard M, Shirakata Y, Chandad F, Zhang Y (2016) Osteoinductive potential of 4 commonly employed bone grafts. Clinical oral investigations. doi:10.1007/s00784-016-1724-4

17. Boyan BD, Ranly DM, Schwartz Z (2006) Use of growth factors to modify osteoinductivity of demineralized bone allografts: lessons for tissue engineering of bone. Dent Clin N Am 50:217-228. doi:10.1016/j.cden.2005.11.007

18. Daculsi G, Laboux O, Malard O, Weiss P (2003) Current state of the art of biphasic calcium phosphate bioceramics. J Mater Sci Mater Med 14:195-200

19. Yip I, Ma L, Mattheos N, Dard M, Lang NP (2015) Defect healing with various bone substitutes. Clin Oral Implants Res 26:606-614

20. Dahlin C, Obrecht M, Dard M, Donos N (2015) Bone tissue modelling and remodelling following guided bone regeneration in combination with biphasic calcium phosphate materials presenting different microporosity. Clin Oral Implants Res 26:814-822

21. Miron RJ, Bosshardt DD, Gemperli AC, Dard M, Buser D, Gruber $\mathrm{R}$, Sculean A (2014) In vitro characterization of a synthetic calcium phosphate bone graft on periodontal ligament cell and osteoblast behavior and its combination with an enamel matrix derivative. Clinical oral investigations 18:443-451

22. Miron RJ, Bosshardt DD, Buser D, Zhang Y, Tugulu S, Gemperli A, Dard M, Caluseru OM, Chandad F, Sculean A (2015) Comparison of the capacity of enamel matrix derivative gel and enamel matrix derivative in liquid formulation to adsorb to bone grafting materials. $\mathrm{J}$ Periodontol 86:578-587. doi:10.1902/jop.2015.140538

23. Miron RJ, Hedbom E, Saulacic N, Zhang Y, Sculean A, Bosshardt DD, Buser D (2011) Osteogenic potential of autogenous bone grafts harvested with four different surgical techniques. J Dent Res 90: 1428-1433. doi: $10.1177 / 0022034511422718$

24. Rechendorff K, Hovgaard MB, Foss M, Zhdanov V, Besenbacher F (2006) Enhancement of protein adsorption induced by surface roughness. Langmuir 22:10885-10888
25. Bormann N, Pruss A, Schmidmaier G, Wildemann B (2010) In vitro testing of the osteoinductive potential of different bony allograft preparations. Arch Orthop Trauma Surg 130:143-149. doi:10.1007/s00402-009-0908-7

26. Vaziri S, Vahabi S, Torshabi M, Hematzadeh S (2012) In vitro assay for osteoinductive activity of different demineralized freeze-dried bone allograft. Journal of periodontal \& implant science 42:224-230

27. Valerio P, Pereira MM, Goes AM, Leite MF (2004) The effect of ionic products from bioactive glass dissolution on osteoblast proliferation and collagen production. Biomaterials 25:2941-2948

28. Tang Z, Wang Z, Qing F, Ni Y, Fan Y, Tan Y, Zhang X (2015) Bone morphogenetic protein Smads signaling in mesenchymal stem cells affected by osteoinductive calcium phosphate ceramics. J Biomed Mater Res A 103:1001-1010. doi:10.1002/jbm.a.35242

29. Schwartz Z, Somers A, Mellonig JT, Carnes DL Jr, Wozney JM, Dean DD, Cochran DL, Boyan BD (1998) Addition of human recombinant bone morphogenetic protein-2 to inactive commercial human demineralized freeze-dried bone allograft makes an effective composite bone inductive implant material. J Periodontol 69:1337-1345

30. Bergeron E, Senta H, Mailloux A, Park H, Lord E, Faucheux N (2009) Murine preosteoblast differentiation induced by a peptide derived from bone morphogenetic proteins-9. Tissue Eng A 15: 3341-3349. doi:10.1089/ten.TEA.2009.0189

31. Park H, Drevelle O, Daviau A, Senta H, Bergeron E, Faucheux N (2013) Preventing MEK1 activation influences the responses of human osteosarcoma cells to bone morphogenetic proteins 2 and 9. Anti-Cancer Drugs 24:278-290. doi:10.1097/CAD.0b013 e32835cbde7

32. Nakamura T, Shinohara Y, Momozaki S, Yoshimoto T, Noguchi K (2013) Co-stimulation with bone morphogenetic protein-9 and FK506 induces remarkable osteoblastic differentiation in rat dedifferentiated fat cells. Biochem Biophys Res Commun 440: 289-294. doi:10.1016/j.bbrc.2013.09.073

33. Wang JH, Liu YZ, Yin LJ, Chen L, Huang J, Liu Y, Zhang RX, Zhou LY, Yang QJ, Luo JY, Zuo GW, Deng ZL, He BC (2013) BMP9 and COX-2 form an important regulatory loop in BMP9induced osteogenic differentiation of mesenchymal stem cells. Bone 57:311-321. doi:10.1016/j.bone.2013.08.015

34. Sreekumar V, Aspera-Werz RH, Tendulkar G, Reumann MK, Freude T, Breitkopf-Heinlein K, Dooley S, Pscherer S, Ochs BG, Flesch I, Hofmann V, Nussler AK, Ehnert S (2016) BMP9 a possible alternative drug for the recently withdrawn BMP7? New perspectives for (re-)implementation by personalized medicine. Arch Toxicol. doi:10.1007/s00204-016-1796-6 